\section{(A) Check for updates}

Cite this: Org. Chem. Front., 2019, 6 , 1064

DOI: $10.1039 /$ c9qo90021g

rsc.li/frontiers-organic

\title{
Correction: Metal-free tandem reaction synthesis of spiro-cyclopropyl fused pyrazolin-5-one derivatives
}

\author{
Man Liu, ${ }^{a}$ Chen-Fei Liu, ${ }^{a}$ Jing Zhang, ${ }^{a}$ Yan-Jun $\mathrm{Xu}^{\star b}$ and Lin Dong (D) *a \\ Correction for 'Metal-free tandem reaction synthesis of spiro-cyclopropyl fused pyrazolin-5-one deriva- \\ tives' by Man Liu et al., Org. Chem. Front., 2019, 6, 664-668.
}

The authors regret that in Fig. 1, Table 2 and Scheme 3 previous versions of the graphics were inadvertently included above the correct graphics. The correct versions are shown below.

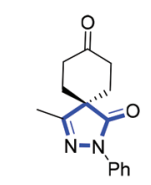

Antibacterial agent

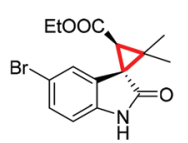

NNRTIs HIV-1 inhibitor

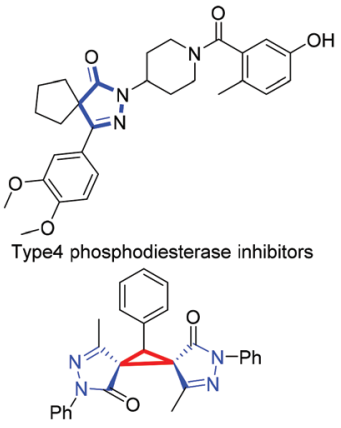

AGE formation inhibitor

Fig. 1 Bioactive spiro-pyrazolone heterocyclic molecules.

${ }^{a}$ Key Laboratory of Drug-Targeting and Drug Delivery System of the Education Ministry, West China School of Pharmacy, Sichuan University, Chengdu 610041, China. E-mail: dongl@scu.edu.cn

${ }^{b}$ College of Chemistry and Material Science, Sichuan Normal University, Chengdu, Sichuan 610066, China. E-mail: xuyj@sicnu.edu.cn 
Table 2 Substrate scope of $N$-arylpyrazol-5-ones ${ }^{a}$

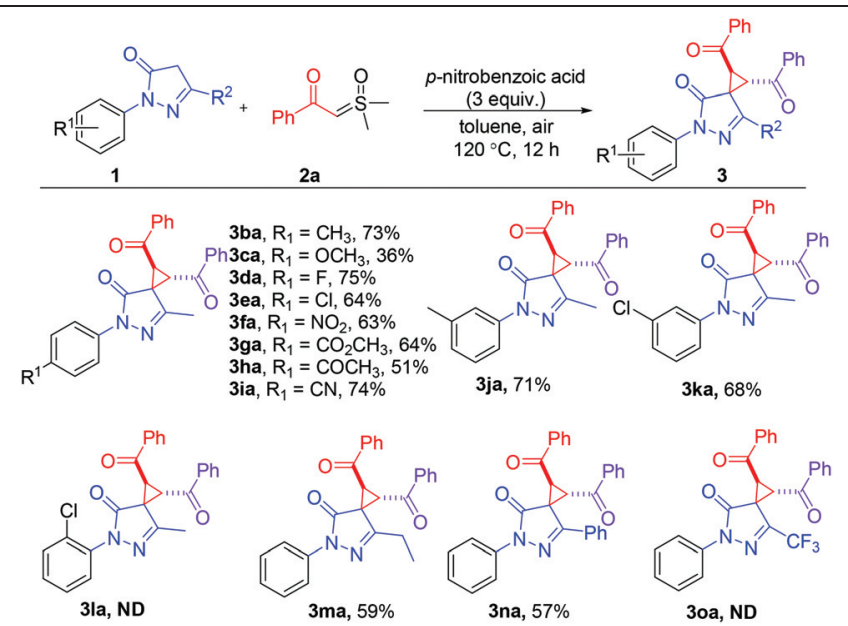

${ }^{a}$ Unless otherwise mentioned all reactions were performed with $0.05 \mathrm{mmol}$ of $1,3.0$ equiv. of $2 \mathrm{a}, 3.0$ equiv. of $p$-nitrobenzoic acid, toluene $(0.5 \mathrm{~mL}), 120^{\circ} \mathrm{C}, 12 \mathrm{~h}$, under air. Isolated yield.



Scheme 3 Proposed reaction mechanism.

The Royal Society of Chemistry apologises for these errors and any consequent inconvenience to authors and readers. 